\title{
Parameter Estimation for Condition Monitoring of PMSM Stator Winding and Rotor Permanent Magnets
}

\author{
Kan Liu, Z.Q. Zhu, Fellow, IEEE, and David A. Stone
}

\begin{abstract}
Winding resistance and rotor flux linkage are important to controller design and condition monitoring of a surface-mounted permanent magnet synchronous machine (PMSM) system. In this paper, an online method for simultaneously estimating the winding resistance and rotor flux linkage of a PMSM is proposed, which is suitable for application under constant load torque. It is based on a proposed full rank reference/variable model. Under constant load torque, a short pulse of $i_{d} \neq 0$ is transiently injected into $d$-axis current, and two sets of machine rotor speeds, currents and voltages corresponding to $i_{d}=0$ and $i_{d} \neq 0$ are then measured for estimation. Since the torque is kept almost constant during the transient injection, thanks to the moment of system inertia and negligible reluctance torque, the variation of rotor flux linkage due to injected $i_{d} \neq 0$ can be taken into account by using the equation of constant torque without measuring the load torque, and is then associated with the two sets of machine equations for simultaneously estimating winding resistance and rotor flux linkage. Further, the proposed method does not need the values of $d q$-axis inductances, while the influence from the non-ideal voltage measurement, which will cause an ill-conditioned problem in the estimation, has been taken into account and solved by error analysis. This method is finally verified on two prototype PMSMs and shows good performance.

Index Terms - condition monitoring, ill-conditioned problem, magnetic flux linkage, neural networks, permanent magnet machines, parameter estimation, rotor flux linkage, stator winding resistance
\end{abstract}

\section{NOMENCLATURE}

$R \quad$ Stator winding resistance $(\Omega)$.

$R_{c} \quad$ Core-loss resistance $(\Omega)$.

$L_{d}, L_{q} \quad d q$-axis inductances $(\mathrm{H})$.

$\psi_{m} \quad$ Rotor flux linkage (Wb).

$u_{d}, u_{q} \quad$ Actual $d q$-axis voltages $(\mathrm{V})$.

$i_{d}, i_{q} \quad$ Actual $d q$-axis currents (A).

$T_{e} \quad$ Electromagnetic torque $(\mathrm{Nm})$.

Denotes a variable specified by PI regulator.

$\wedge \quad$ Denotes an estimated value.

$0,1 \quad$ Denotes the machine parameter and the measured data when $i_{d}=0$ and $i_{d} \neq 0$, respectively.

$u_{d}{ }^{*}, u_{q}{ }^{*} \quad d q$-axis reference voltages measured from the PI regulators $(\mathrm{V})$.

$u_{d}^{e r r}, u_{q}^{\text {err }} \quad$ Total voltage measurement error in $d q$-axis (V).

$\hat{R} \quad$ Estimated stator winding resistance $(\Omega)$.

Manuscript received June 14, 2012. Revised October 30, 2012. Accepted for publication December 24, 2012. Copyright (c) 2009 IEEE. Personal use of this material is permitted. However, permission to use this material for any other purposes must be obtained from the IEEE by sending a request to pubs-permissions@ieee.org.

K. Liu, Z.Q. Zhu and D.A. Stone are with the Department of Electronic and Electrical Engineering, University of Sheffield, UK (e-mail: lkan@live.cn; Z.Q.Zhu@sheffield.ac.uk; d.a.stone@sheffield.ac.uk).

\author{
$\hat{\psi}_{m} \quad$ Estimated rotor flux linkage (Wb). \\ $U \quad$ Distorted voltage due to the variation of DC bus \\ voltage and zero shift in the amplifier (V). \\ $V_{\text {com }} \quad$ Constant of distorted voltage due to inverter \\ nonlinearity in $d q$-axis reference frame $(\mathrm{V})$. \\ $V_{d c} \quad$ Actual DC link voltage (V). \\ $V_{m} \quad$ Measured DC link voltage (V). \\ $\omega, \theta \quad$ Electrical angular speed ( $\mathrm{rad} / \mathrm{s})$ and rotor position \\ (rad).
}

\section{INTRODUCTION}

P ermanent magnet synchronous machines are now widely employed in industrial servo drives, electrical/hybrid electric vehicles, and wind power generators, etc., since they have high torque and power density and high efficiency. However, for most applications, it is important to obtain accurate electromagnetic parameters for control system design [1], [35]-[38], online fault diagnosis [17] and rotor/stator condition monitoring [16]. Traditionally, these machine parameters such as stator winding resistance and rotor flux linkage are measured using additional instrumentation, which increases system complexity and set up time, and requires the machine to work on no load due to the safety issue in measurement. In reality, it is seldom possible that all the required instrumentation is available for the parameter measurement, and furthermore, the desired parameter value is usually different on load from the value on no load. However, no matter it is for controller design or condition monitoring, it is preferable that the machine parameters can be observed when it is actually on load. Thus, in reality, online parameter estimation technologies such as model reference adaptive system (MRAS) [2], recursive least square (RLS) [17] and extended Kalman filters (EKF) [7] are customarily employed for estimating the desired parameter values rather than using additional instruments, especially for online monitoring the stator and rotor conditions.

However, it is known in system identification theory that it is impossible to ensure estimation accuracy if the estimation is based on a rank deficient reference/variable model, and the steady state $d q$-axis equation of PMSM shows that it is a rank deficient equation for simultaneously estimating winding $d q$-axis inductances, resistance and rotor flux linkage. Therefore, as detailed in [3], [22], [30] and [34], it is impossible to simultaneously estimate winding resistance and rotor flux linkage using only one set of PMSM states. Taking the method of [1] for example, it did not take into account the rank of the utilized reference model, and its estimator failed to estimate the stator winding resistance due to ill-convergence. For solving this rank deficient problem, some literature [2]-[6], [32]-[34] 
proposes to estimate each parameter separately by fixing other parameters to their nominal values to get a full rank reference/variable model. However, what could be worse is that if the winding resistance and rotor flux linkage are not simultaneously estimated but estimated separately, the estimation of the two parameters will converge to the wrong points [22] due to the mismatching of un-estimated parameters. For example, the method in [3] proposed two schemes for estimating winding resistance and rotor flux linkage, respectively. In scheme $\mathrm{I}$, the stator winding resistance is estimated while the rotor flux linkage and the inductance are set to be nominal values. In scheme II, the rotor flux linkage is estimated while the winding inductance and resistance are set to be nominal values. However, it is verified in [22] that the method in [3] will suffer from the mismatch between the nominal and actual parameter values, and similar problem also occurs in the method presented in [2], which is proposed to estimate the winding resistance and inductance simultaneously while the rotor flux linkage is set to be its nominal value.

In practice, parameter values such as PMSM stator winding resistance and rotor flux linkage are both required for condition monitoring of stator winding and rotor permanent magnets, for example, their temperature rise. In this case, the estimation of winding resistance and rotor flux linkage should be performed simultaneously otherwise this will also suffer from the mismatch between the nominal and actual parameter values. For example, assuming that if there is a variation in the stator winding and the scheme II of [3] is employed for monitoring the variation of rotor flux linkage, the variation of stator winding will influence on the result of estimating rotor flux linkage and it is impossible to distinguish whether this variation comes from the stator winding or the rotor. Thus, the winding resistance and rotor flux linkage should be estimated simultaneously and the rank deficient problem should be solved prior to the estimator design. To overcome this rank deficient problem, perturbation signals such as $i_{d} \neq 0$ and DC voltage offset are injected into the system to build a full rank reference model for estimation [7]-[13], [22]. It is firstly reported in [7]-[9] that by setting the $d q$-axis inductances to be their nominal values, the $d q$-axis equation can be made full rank for simultaneously estimating the winding resistance and rotor flux linkage with the injection of $i_{d} \neq 0$, in which the variation of inductance and non-ideal voltage measurement such as the inverter nonlinearities, the variation of DC bus voltage and zero shift in the amplifier, are not taken into account. Taking the method presented in [8] as an example, it proposed to inject alternating $d$-axis current to activate the winding resistance and rotor flux linkage estimation. However, it was proved in [22] that the method of [8] was sensitive to the amplitude of injected $i_{d} \neq 0$ because it did not account for the variation of inductance and non-ideal voltage measurement due to $i_{d} \neq 0$. In addition, the method in [10] proposes to estimate the $d q$-axis inductances, winding resistance and rotor flux linkage simultaneously by two schemes with different convergence speeds as well as injecting a three-level perturbation in $d$-axis current. However, the convergence of the estimated parameter was still sensitive to the perturbation and the unstable convergence in some experiments might be caused by saturation. Further, an error analysis based full rank reference/variable model was proposed in [22] for simultaneously estimating the winding resistance, rotor flux linkage and $d q$-axis inductances of a non-salient pole PMSM by a transient injection of $i_{d} \neq 0$. It took into account the ill-conditioned problem (See Appendix B) caused by the variation of $d q$-axis inductances and rotor flux linkage due to the injected $i_{d} \neq 0$. However, it did not take into account the influence from non-ideal voltage measurement. In addition, it is also reported in [11]-[13] that it is possible to online estimate the winding resistance by transiently superimposing a DC voltage offset in one or more of the machine phases, by which the estimation of winding resistance will be dependent of the variation of inductance and rotor flux linkage. This kind of method [11]-[13] should take into account the influence of injected DC voltage offset on the system stability and the amplitude of injected DC bias should be minimized.

On the other hand, the methods in [14]-[16] and [19] propose to estimate the winding resistance and rotor flux linkage with assistance from measuring instruments. For example, the methods presented in [14] and [15] propose to add a load test to aid the rotor flux linkage estimation and it is effective if the torque is accurately measured. In addition, since it is much cheaper to bury a thermocouple in stator winding than to add a torque transducer, the method in [16] proposed to monitor the variation of rotor flux linkage with the assistance from the measured stator winding temperature. The method in [19] proposed an online multi-parameter identification method based on power and torque measurement technique. Parameters such as copper loss, stator loss, mechanical loss and stray loss are estimated with assistance from high accuracy digital power meter and torque transducer.

In addition, it is reported that in some applications, it is acceptable to estimate the winding resistance and rotor flux linkage approximately by changing the working condition. For example, it is proposed in [17] to simultaneously estimate the winding resistance and rotor flux linkage under varying load torque, although, this will not be effective under constant load torque. It is proposed in [18] that the winding resistance can be approximately estimated at low speed while the rotor flux linkage can be approximately estimated at medium and high speed. It is proposed in [20] that the winding resistance and rotor flux linkage can be estimated separately before and after the starting of the PMSM. In [21] that the rotor flux linkage can be estimated at standstill by tuning the PI constants and measuring sets of step responses.

In this paper, a method based on a full rank reference/variable model is proposed for simultaneously estimating the winding resistance and rotor flux linkage of a PMSM, which can be used as condition indicators (such as temperature rises) of stator winding and rotor permanent magnet. Under constant load torque, a perturbation of $i_{d} \neq 0$ is transiently injected into $d$-axis current and two sets of PMSM rotor speeds, currents and voltages corresponding to $i_{d}=0$ and $i_{d} \neq 0$ are then measured for estimation. Since the torque is kept almost constant due to the system mechanical inertia and fast response of the current-loop PI controller during the transient injection, the variation of rotor flux linkage due to injected $i_{d}>0$ can be obtained by using the equation of constant load torque without measuring the physical load torque, and is then associated with the two sets of machine equations for simultaneously estimating winding resistance and rotor flux 
linkage. Different from the existing methods [7]-[10], [20] based on injecting $i_{d} \neq 0$, the proposed estimation does not need the nominal value of any parameters, and its accuracy will not suffer from the machine parameter variation due to $i_{d} \neq 0$. Furthermore, compared with [21], the proposed estimation will not be influenced by the variation of $d q$-axis inductances and rotor flux linkage due to $i_{d} \neq 0$ while the ill-conditioned problem caused by non-ideal voltage measurement has been taken into account and solved by optimizing the amplitude of injected $i_{d}$. The proposed method is experimentally employed for monitoring the stator winding and rotor permanent magnet conditions in a small power PMSM and a relatively large power PMSM, respectively.

\section{PMSM MODEL}

Since the cross-coupling effect is usually negligible at steady-state, the $d q$-axis equations of the PMSM shown in (1) are usually employed for the parameter estimation of PMSM [1]-[10], [18], [22], and [28].

$$
\left\{\begin{array}{l}
\frac{d i_{d}}{d t}=-\frac{R}{L_{d}} i_{d}+\frac{L_{q}}{L_{d}} \omega i_{q}+\frac{u_{d}}{L_{d}} \\
\frac{d i_{q}}{d t}=-\frac{R}{L_{q}} i_{q}-\frac{L_{d}}{L_{q}} \omega i_{d}+\frac{u_{q}}{L_{q}}-\frac{\psi_{m}}{L_{q}} \omega \\
T_{e}=1.5 p\left[\psi_{m} i_{q}+\left(L_{d}-L_{q}\right) i_{d} i_{q}\right]
\end{array}\right.
$$

In steady-state, the $d q$-axis machine equations can be simplified as follows [23]:

$$
\begin{aligned}
& u_{d}(k)=R i_{d}(k)-L_{q} \omega(k) i_{q}(k) \\
& u_{q}(k)=R i_{q}(k)+L_{d} \omega(k) i_{d}(k)+\psi_{m} \omega(k)
\end{aligned}
$$

' $k$ ' is the index of the discrete sampling instants in the drive system. However, as can be seen from (2), the rank of (2) is two while there are four parameters such as $d q$-axis inductances, winding resistance and rotor flux linkage. Therefore, it is impossible to ensure the estimation accurately converge to the right point and a current pulse is injected to obtain one more set of $d q$-axis state equation.

The schematic diagram for measuring and recording two sets of rotor speed, $d q$-axis currents and voltages is shown in Fig. 1, in which the setup time delay is to ensure the measurement of Datal is started after the settling of step transients correlated to the $i_{d}$ pulse. From Fig. 1, the two measured sets of PMSM data correspond to two sets of PMSM state equations and can be combined as a whole system to give:

$$
\begin{aligned}
& u_{d 0}\left(k_{0}\right)=-L_{q 0} \omega\left(k_{0}\right) i_{q 0}\left(k_{0}\right) \\
& u_{q 0}\left(k_{0}\right)=R i_{q 0}\left(k_{0}\right)+\psi_{m 0} \omega\left(k_{0}\right) \\
& u_{d}\left(k_{1}\right)=R i_{d}\left(k_{1}\right)-L_{q} \omega\left(k_{1}\right) i_{q}\left(k_{1}\right) \\
& u_{q}\left(k_{1}\right)=R i_{q}\left(k_{1}\right)+L_{d} \omega\left(k_{1}\right) i_{d}\left(k_{1}\right)+\psi_{m} \omega\left(k_{1}\right)
\end{aligned}
$$

In (3), the variables and parameters with and without the subscripts ' 0 ' correspond to the measured data when $i_{d}=0$ and $i_{d} \neq 0$, respectively. ' $k_{0}$ ' and ' $k_{1}$ ' are the index of the $k_{0}$-th and $k_{1}$-th measured instant of Data0 and Data1, respectively. Since the mechanical and temperature time constants are much larger than the electrical constant, the rotor speed $\left(\omega\left(k_{0}\right)=\omega\left(k_{1}\right)\right)$ and winding resistance will be almost constant during the measuring data. To reduce the influence on the output torque, the width of the injected perturbation in the $d$-axis current is limited to a short time, which will be discussed in the following sections. The recorded data can be used to calculate iteratively until the estimated results converged to the final value in the background application. Since the machine is under constant load torque, and the rotor speed is also kept constant, the electromagnetic torque at $i_{d}=0$ and $i_{d} \neq 0$ can be:

$$
\begin{aligned}
T_{e}\left(k_{0}\right) & =1.5 p \psi_{m 0} i_{q 0}\left(k_{0}\right) \\
& =T_{e}\left(k_{1}\right)=1.5 p\left[\psi_{m} i_{q}\left(k_{1}\right)+\left(L_{d}-L_{q}\right) i_{d}\left(k_{1}\right) i_{q}\left(k_{1}\right)\right]
\end{aligned}
$$

\section{PROPOSED FULL RANK ESTIMATION}

\section{A. Proposed Full Rank Model and Estimator Design}

As can be seen from (4), since the electromagnetic torque is constant during the estimation, the rotor flux linkage after the injection of $i_{d} \neq 0$ can be derived by solving (4):

$\psi_{m}=\psi_{m 0} \frac{i_{q 0}\left(k_{0}\right)}{i_{q}\left(k_{1}\right)}+\left(L_{q}-L_{d}\right) i_{d}\left(k_{1}\right)$

Substitute (5) into ( $3 \mathrm{~d})$, it becomes:

$u_{q}\left(k_{1}\right)=R i_{q}\left(k_{1}\right)+\left(\psi_{m 0} \frac{i_{q 0}\left(k_{0}\right)}{i_{q}\left(k_{1}\right)}+L_{q} i_{d}\left(k_{1}\right)\right) \omega\left(k_{1}\right)$

Thus, (6) can be obtained as follows:

$u_{q}\left(k_{1}\right) i_{q}\left(k_{1}\right)=R i_{q}^{2}\left(k_{1}\right)+\left(\psi_{m 0} i_{q 0}\left(k_{0}\right)+L_{q} i_{d}\left(k_{1}\right) i_{q}\left(k_{1}\right)\right) \omega\left(k_{1}\right)$

(3c) multiplied by $i_{d}\left(k_{1}\right)$ becomes:

$u_{d}\left(k_{1}\right) i_{d}\left(k_{1}\right)=R i_{d}^{2}\left(k_{1}\right)-L_{q} \omega\left(k_{1}\right) i_{q}\left(k_{1}\right) i_{d}\left(k_{1}\right)$

Substitute (7) into (6), it becomes:

$u_{q}\left(k_{1}\right) i_{q}\left(k_{1}\right)+u_{d}\left(k_{1}\right) i_{d}\left(k_{1}\right)=R\left(i_{q}^{2}\left(k_{1}\right)+i_{d}^{2}\left(k_{1}\right)\right)+\psi_{m 0} i_{q 0}\left(k_{0}\right) \omega\left(k_{1}\right)$

Combine (8) and (3b), it becomes:

$u_{q}\left(k_{1}\right) i_{q}\left(k_{1}\right)+u_{d}\left(k_{1}\right) i_{d}\left(k_{1}\right)=R\left(i_{q}^{2}\left(k_{1}\right)+i_{d}^{2}\left(k_{1}\right)\right)+\psi_{m 0} i_{q 0}\left(k_{0}\right) \omega\left(k_{1}\right)$

$u_{q 0}\left(k_{0}\right)=R i_{q 0}\left(k_{0}\right)+\psi_{m 0} \omega\left(k_{0}\right)$

It can be seen from the derivation process shown in (5)-(9) that all the $d q$-axis inductance terms $\left(L_{q}, L_{d}, L_{q 0}, L_{d 0}\right)$ and the rotor flux linkage term at $i_{d} \neq 0\left(\psi_{m}\right)$ are cancelled and only two terms, rotor flux linkage at $i_{d}=0\left(\psi_{m 0}\right)$ and winding resistance $(R)$, exist in (9), of which the rank number is two. Thus, the winding resistance and rotor flux linkage can be solved from (9) without influence from the variation of $d q$-axis inductances and rotor flux linkage due to $i_{d} \neq 0$ and (9) can ensure the estimation will correctly converge to the right point.

Since the Neural Network technology is widely employed in machine parameter estimation [22], [24], the Adaline algorithm [25] is utilized to design the winding resistance and rotor flux linkage estimators, which are derived from (9) and shown in (10) and (11), respectively. The design processes of the two estimators are detailed in Appendix A. 


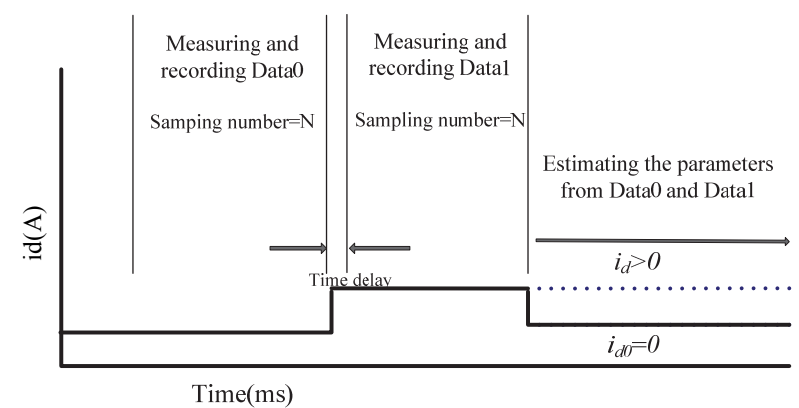

Fig. 1. Measuring and recording data when $i_{d 0}=0$ and $i_{d} \neq 0$, respectively.

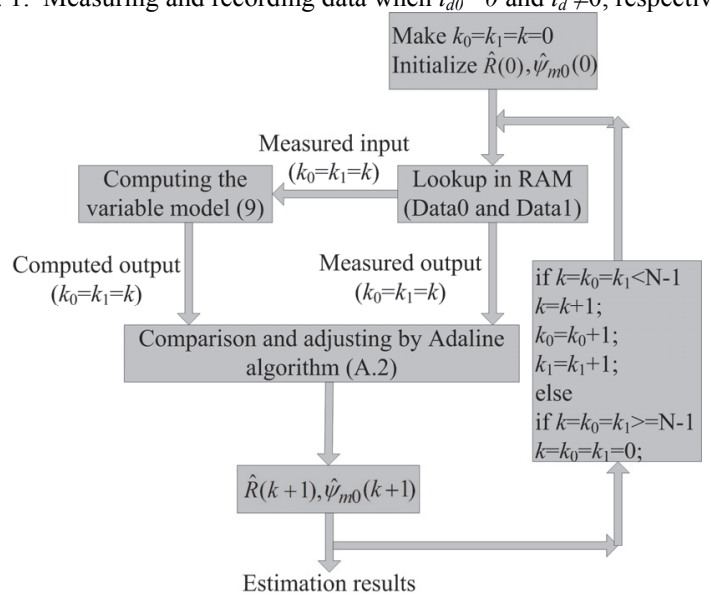

Fig. 2. Iterative computation processes of proposed Adaline NN based estimation strategy.

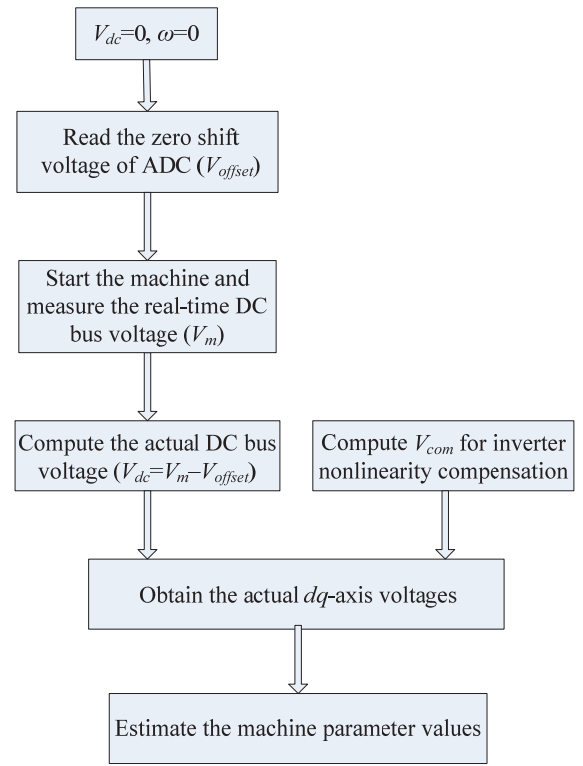

Fig. 3. Schematic diagram of the compensation of measured voltage.

$$
\begin{gathered}
\hat{R}(k+1)=\hat{R}(k)+2 \eta\left(i_{q}^{2}\left(k_{1}\right)+i_{d}^{2}\left(k_{1}\right)-i_{q 0}^{2}\left(k_{0}\right)\right)\left(u_{q}\left(k_{1}\right) i_{q}\left(k_{1}\right)+\right. \\
\left.u_{d}\left(k_{1}\right) i_{d}\left(k_{1}\right)-u_{q 0}\left(k_{0}\right) i_{q 0}\left(k_{0}\right)-O_{R}(k)\right) \\
\hat{\psi}_{m 0}(k+1)=\hat{\psi}_{m 0}(k)+2 \eta \omega\left(k_{0}\right)\left(u_{q 0}\left(k_{0}\right)-\hat{u}_{q 0}\left(k_{0}\right)\right)
\end{gathered}
$$

The schematic diagram of the whole estimation is shown in Fig. 2. The estimation will be started after the completion of measuring and recording of Data0 and Data1. As can be seen from Fig. 2, since Data0 and Data1 are stored in RAM, the numbering can be reset to be $k=k_{0}=k_{1}=0$ at the beginning of the estimation and the two stored sets of data are simultaneously sent to the proposed estimation method for iterative computation from 0 to $\mathrm{N}-1$ in sequence.

Although the proposed reference model (9) is full rank, the accuracy of estimators (10) and (11) still suffers from the ill-conditioned problem caused by the non-ideal voltage measurement such as with inverter nonlinearities, the variation of DC bus voltage and zero shift in the amplifier. In Appendix $\mathrm{B}$, the definition of the ill-conditioned problem is briefly introduced and the solution for the ill-conditioned problem due to non-ideal voltage measurement will be discussed in following section.

\section{B. Analysis of Ill-conditioned Problem}

As detailed in [26]-[28], the steady-state equations of a PMSM including the voltage nonlinearities can be shown as follows:

$$
\begin{gathered}
{\left[\begin{array}{l}
u_{d}(k) \\
u_{q}(k)
\end{array}\right]=\left[\begin{array}{l}
u_{d}{ }^{*}(k)-u_{d}^{e r r} \\
u_{q}^{*}(k)-u_{q}^{e r r}
\end{array}\right]=\left[\begin{array}{c}
-L_{q} i_{q}(k) \\
L_{d} i_{d}(k)+\psi_{m}
\end{array}\right] \omega(k)+R\left[\begin{array}{l}
i_{d}(k) \\
i_{q}(k)
\end{array}\right]} \\
{\left[\begin{array}{c}
u_{d}^{e r r} \\
u_{q}^{e r r}
\end{array}\right]=U\left[\begin{array}{c}
\cos (\phi) \\
-\sin (\phi)
\end{array}\right]-\left[\begin{array}{c}
D d(k) V_{\text {com }} \\
D q(k) V_{\text {com }}
\end{array}\right]}
\end{gathered}
$$

where $u_{d}^{\text {err }}$ and $u_{q}^{\text {err }}$ are the total voltage nonlinearities in $d q$-axis. $V_{\text {com }}, u_{d}{ }^{*}$ and $u_{q}{ }^{*}$ are the constants of distorted voltage due to VSI nonlinearity and $d q$-axis reference voltages are measured from the PI regulators, respectively. $\phi$ is the angle between voltage vector and $q$-axis. $D d$ and $D q$ are functions of rotor position $\theta$ and the directions of three phase currents, which can be expressed as follows:

$$
\begin{aligned}
& {\left[\begin{array}{c}
D d \\
D q
\end{array}\right]=2\left[\begin{array}{ccc}
\cos (\theta) & \cos \left(\theta-\frac{2 \pi}{3}\right) & \cos \left(\theta+\frac{2 \pi}{3}\right) \\
-\sin (\theta) & -\sin \left(\theta-\frac{2 \pi}{3}\right) & \sin \left(\theta-\frac{\pi}{3}\right)
\end{array}\right]\left[\begin{array}{l}
\operatorname{sign}\left(i_{a s}\right) \\
\operatorname{sign}\left(i_{b s}\right) \\
\operatorname{sign}\left(i_{c s}\right)
\end{array}\right]} \\
& \operatorname{sign}(i)=\left\{\begin{array}{l}
1, i>=0 \\
-1, i<0
\end{array}\right. \\
& V_{\text {com }}=\frac{1}{6}\left(\frac{T_{o f f}-T_{o n}-T_{d}}{T_{s}} V_{d c}-V_{c e 0}-V_{d 0}\right)
\end{aligned}
$$

where $T_{d}$ is the control dead time of the switch; $T_{o n}$ and $T_{\text {off }}$ are the turn on/off time delay of the switch; $V_{c e 0}$ and $V_{d 0}$ are the threshold voltages of the active switch and freewheeling diode, respectively [29].

From (12), it is evident that terms such as $u_{d}^{\text {err }}$ and $u_{q}^{\text {err }}$ will introduce a distortion into the measured $d q$-axis voltages which will cause the estimation result to be different from the actual value. Thus, the measured $d q$-axis voltages from the PI regulators should be compensated prior to the estimation. Furthermore, since the compensation cannot be $100 \%$ accurate, the estimation error due to non-ideal compensation should be analyzed and minimized by software approach, for example, error analysis.

The compensation for the non-ideal voltage measurement is divided into three steps:

1. Read the zero shift voltage $V_{\text {offset }}$ of AD converter at 0 speed while $V_{d c}=0$. Thus, the actual DC bus voltage can be obtained by $V_{d c}=V_{m}-V_{\text {offset }}$. 


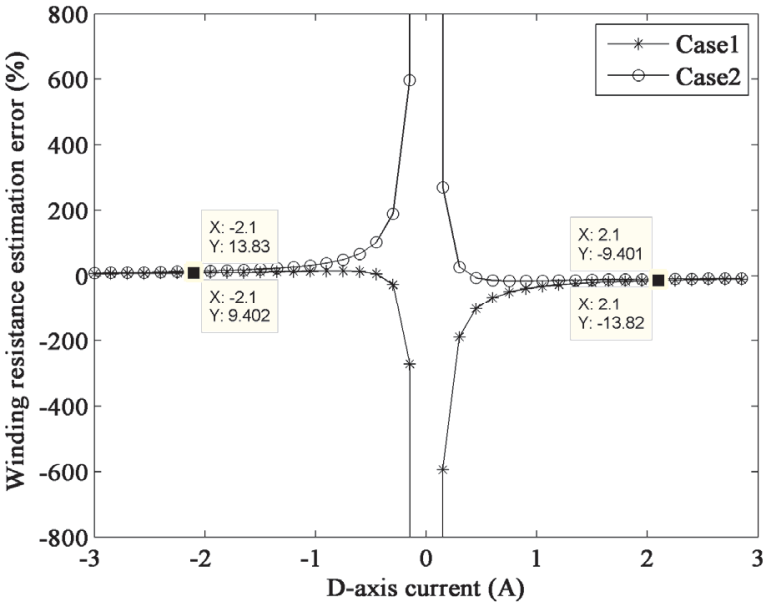

(a)

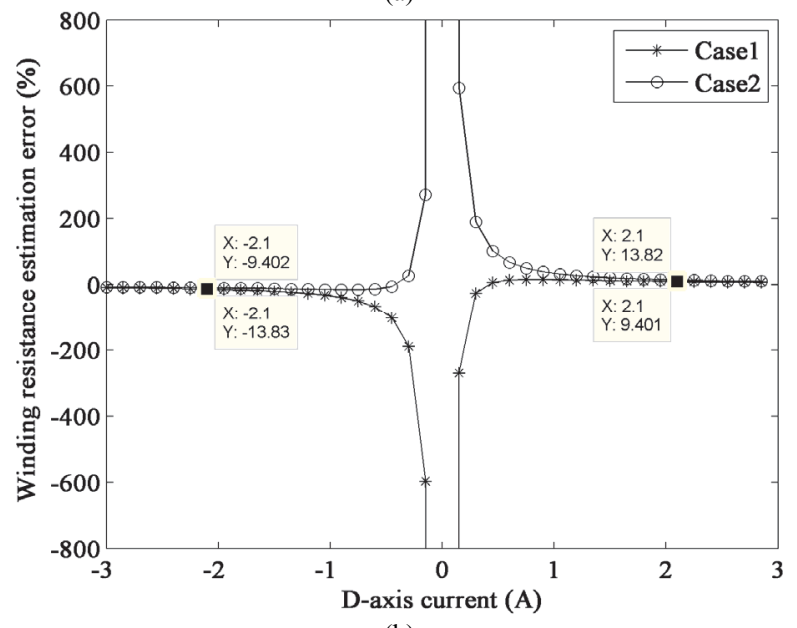

(b)

Fig. 4. Simulated variation of estimation error $R_{\text {err }} / R_{a}$ with $i_{d}$ under different $i_{q}$. (a) Case1: $u_{d}^{e r r}<0, u_{q}^{e r r}-u_{q 0}^{e r r}>0, i_{q}=-2 \mathrm{~A}$ or $u_{d}^{e r r}<0, u_{q}^{e r r}-u_{q 0}^{e r r}<0, i_{q}=2 \mathrm{~A}$. Case2: $u_{d}^{e r r}<0, u_{q}^{e r r}-u_{q 0}^{e r r}>0, i_{q}=2 \mathrm{~A}$ or $u_{d}^{e r r}<0, u_{q}^{e r r}-u_{q 0}^{e r r}<0, i_{q}=-2 \mathrm{~A}$. (b) Case 1: $u_{d}^{e r r}>0, u_{q}^{e r r}-u_{q 0}^{e r r}>0, i_{q}=-2 \mathrm{~A}$. Case 2: $u_{d}^{e r r}>0, u_{q}^{e r r}-u_{q 0}^{e r r}>0, i_{q}$ $=2 \mathrm{~A}$.

2. $V_{\text {com }}$ is computed by using the typical electrical parameters of employed inverter [29].

3. The computed $V_{\text {offset }}$ and $V_{\text {com }}$ will be employed for compensating the $d q$-axis voltages measured from the output of PI regulators.

Fig. 3 shows the above compensation process. By substituting (12) into (9), the winding resistance value including the estimation error $R_{\text {err }}$ due to $u_{d}^{\text {err }}$ and $u_{q}^{\text {err }}$ can be expressed as (14).

$$
R=R_{a}+R_{\text {err }}=\frac{\left(u_{q}+u_{q}^{\text {err }}\right) i_{q}+\left(u_{d}+u_{d}^{\text {err }}\right) i_{d}-\left(u_{q 0}+u_{q 0}^{\text {err }}\right) i_{q 0}}{i_{q}^{2}+i_{d}^{2}-i_{q 0}^{2}}
$$

where $R_{a}$ is the actual winding resistance and $R_{\text {err }}$ is the estimation error due to $u_{d}^{e r r}$ and $u_{q}^{\text {err }}$.

$$
\begin{gathered}
R_{a}=\frac{u_{q} i_{q}+u_{d} i_{d}-u_{q 0} i_{q 0}}{i_{q}^{2}+i_{d}^{2}-i_{q 0}^{2}} \\
R_{e r r}=\frac{u_{q}^{e r r} i_{q}+u_{d}^{e r r} i_{d}-u_{q 0}^{e r r} i_{q 0}}{i_{q}^{2}+i_{d}^{2}-i_{q 0}^{2}}
\end{gathered}
$$

Since the estimation is under constant torque control and the reluctance torque is negligible for a non-salient pole surface mounted PMSM, the $q$-axis current will be almost constant $\left(i_{q}=i_{q 0}\right)$ during the injection of $i_{d}$. Thus, (15) can be simplified to be (16).

$$
R_{\text {err }} \approx \frac{u_{d}^{e r r}}{i_{d}}+\frac{\left(u_{q}^{e r r}-u_{q 0}^{e r r}\right) i_{q}}{i_{d}^{2}}
$$

From (16), it is evident that $R_{e r r}$ is a monotonically decreasing function of $i_{d}$. For parameter estimation, the estimation error $R_{\text {err }}$ can be acceptable if it is negligible compared with its nominal value. (16) shows that $R_{\text {err }}$ can be minimized by increasing the amplitude of $i_{d}$ or minimizing $u_{d}^{\text {err }}$ and $u_{q}^{\text {err }}-u_{q 0}^{\text {err }}$. Since it is impossible to minimize $u_{d}^{e r r}$ and $u_{q}^{e r r}-u_{q 0}^{e r r}$ to be zero due to non-ideal compensation technology, the amplitude of injected $i_{d}$ should be optimized for minimizing $R_{e r r}$. For analysis, assuming that $R_{a}=2.05 \Omega,\left|u_{d}^{\text {err }}\right|=0.5$ and $\left|u_{q}^{\text {err }}-u_{q 0}^{\text {err }}\right|=$ 0.1 , the simulated variation of $R_{e r r}$ with $i_{d}$ under $i_{q}=2 \mathrm{~A}$ and $i_{q}=-2 \mathrm{~A}$ is depicted in Fig. 4, which shows that $R_{\text {err }}$ will be either infinite if $i_{d}$ is close to zero or close to zero if $i_{d}$ is large enough. It can also be explained that a larger amplitude of injected $i_{d}$ will achieve a larger ratio of signal to measurement error, which can improve the estimation accuracy significantly. Further, as can be seen from (16), since there may be an error cancellation between $u_{d}^{\text {err }}$ and $u_{q}^{\text {err }}-u_{q 0}^{\text {err }}$, the signs of $i_{d}, i_{q}, u_{d}^{\text {err }}$ and $u_{q}^{e r r}-u_{q 0}^{e r r}$ can influence the efficiency of minimizing the estimation error by increasing the amplitude of injected $i_{d}$. In reality, the signs of $u_{d}^{e r r}$ and $u_{q}^{e r r}-u_{q 0}^{e r r}$ depend on the power devices and are different in various systems while the sign of $i_{q}$ depends on the operating mode of the machine. Thus, the sign of $i_{d}$ is the only term can be changed for achieving the optimal efficiency of minimizing the estimation error, which can be determined by using error analysis.

\section{EXPERIMENTAL VERIFICATION}

\section{A. Hardware Platform and Control System}

To validate the performance of the proposed method, two prototype PMSMs (Motor1 and Motor2) shown in Fig. 5 are employed for testing and their design parameters are given in Table I and Table II, respectively. Motor 1 is controlled by a TI 2812 DSP and fed by a Mitsubishi PS21867 inverter while Motor 2 is controlled by a DS1006 board and fed by a SEMIX $71 \mathrm{GD} 12 \mathrm{E} 4 \mathrm{~s}$ inverter. In addition, it is obvious that the rated power of Motorl (150W) is relatively small compared with Motor2 $(3 \mathrm{~kW})$. Vector control is employed for testing and its schematic diagram is depicted in Fig. 6.

\section{B. Experimental Validation on Motor 1}

The proposed method is firstly validated on Motor1. As detailed in subsection B of section VI, the estimation result may suffer from the ill-conditioned problem due to the non-ideal voltage measurement, whilst in reality any voltage compensation cannot be $100 \%$ accurate. Thus, the estimation error due to non-ideal voltage measurement and compensation should be minimized by using error analysis. 


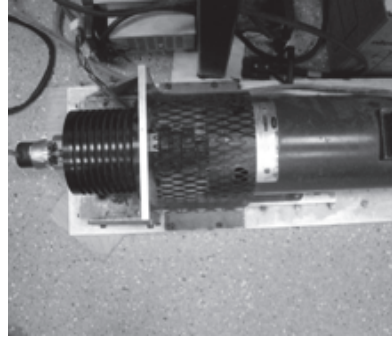

(a)

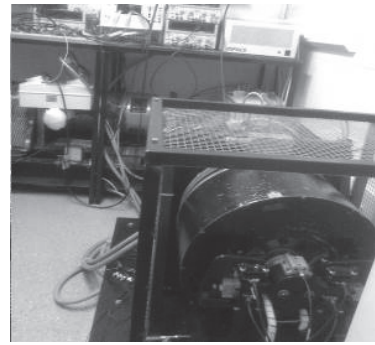

(b)
Fig. 5. Prototype PMSMs. (a) Motor1. (b) Motor2.

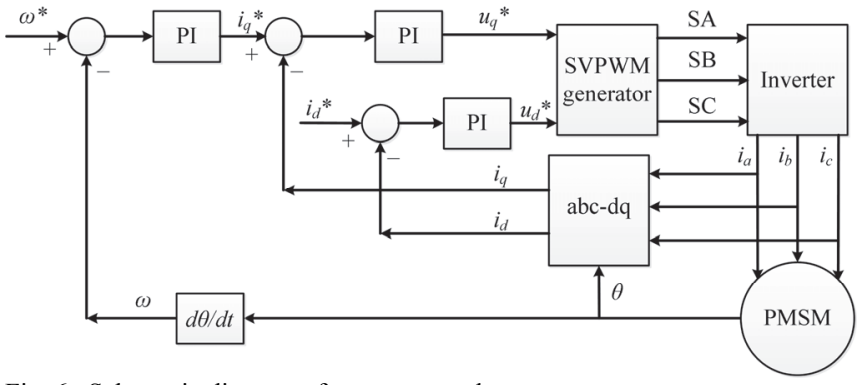

Fig. 6. Schematic diagram of vector control.

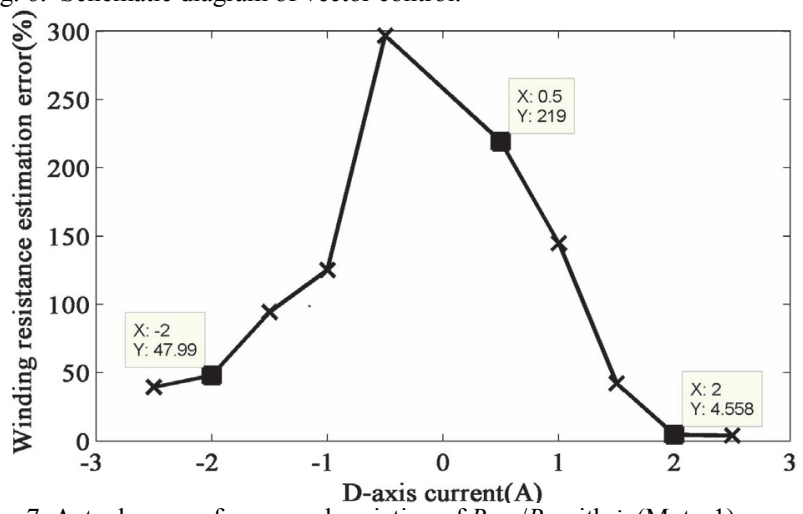

Fig. 7. Actual curve of measured variation of $R_{\text {error }} / R_{a}$ with $i_{d}$ (Motor1).

TABLE I

DESIGN PARAMETERS AND SPECIFICATION OF MOTOR 1

\section{Rated current \\ Rated speed}

DC link voltage

Nominal phase resistance $\left(T=25^{\circ} \mathrm{C}\right)$

Nominal terminal wire resistance

Nominal self inductance

Nominal mutual inductance

Nominal $d q$-axis inductances

Nominal amplitude of flux induced by magnets

Number of pole pairs

Number of stator slots

Note: Nominal values are measured.

TABLE II

DESIGN PARAMETERS AND SPECIFICATION OF MOTOR2

\begin{tabular}{ll}
\hline Rated current & $5 \mathrm{~A}$ \\
Rated speed & $170 \mathrm{rpm}$ \\
DC link voltage & $600 \mathrm{~V}$ \\
Nominal phase resistance $\left(T=20^{\circ} \mathrm{C}\right)$ & $1.880 \Omega$ \\
Nominal terminal wire resistance & $0.125 \Omega$ \\
Nominal $d q$-axis inductances & $8.18 \mathrm{mH}$ \\
Nominal amplitude of flux induced by magnets & $1051.1 \mathrm{mWb}$ \\
Number of pole pairs & 14 \\
Number of stator slots & 84 \\
\hline
\end{tabular}

Note: Nominal values are measured.
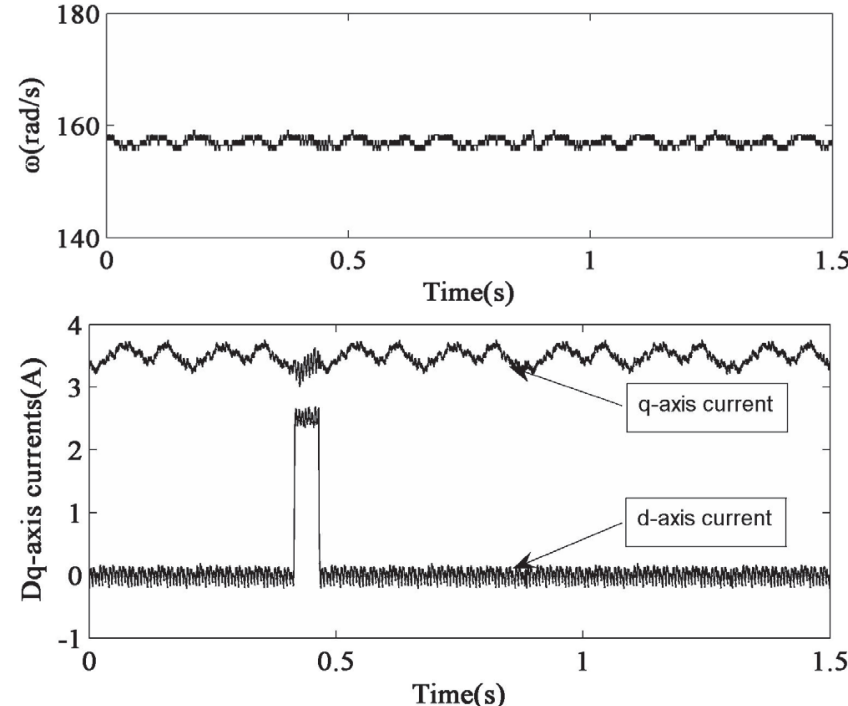

Fig. 8. Measured electrical angular speed (300RPM), $d q$-axis currents, and injected current pulse (Motor1)

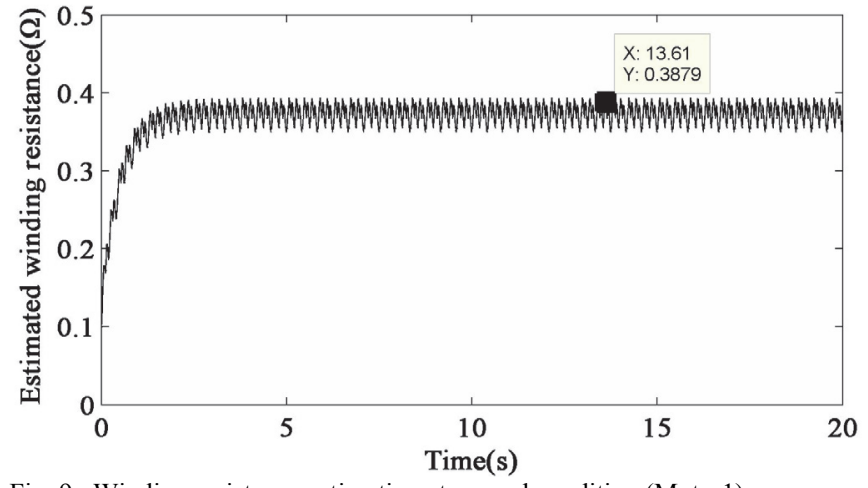

Fig. 9. Winding resistance estimation at normal condition (Motor1).

Fig. 7 shows the error analysis result of estimated winding resistance at different amplitudes of $i_{d} \neq 0$ and the corresponding error analysis process is illustrated below:

a. Measure the winding resistance $\left(R_{a}=0.373 \Omega\right)$ at standstill.

b. Estimate the winding resistance value $(R)$ by estimator $(10)$.

c. The estimation error of (10) due to ill-conditioned problem (or non-ideal voltage measurement) can be $R_{e r r}=R-R_{a}$.

As can be seen from Fig. 7 and Table III, the estimation error $R_{e r r}$ decreases with the increase in the amplitude of $i_{d}$ and it can be negligible when $i_{d} \geq 2 \mathrm{~A}$, which is similar to the simulated result of Case 2 in Fig. 4 (a). Thus, from the error analysis results of Fig. 7 , it is preferable to inject $i_{d}=2.5 \mathrm{~A}$ for the parameter estimation throughout this paper.

Fig. 8 shows the measured currents and electrical angular speed during the injection of $i_{d}$, which shows that the influence of injected $i_{d}$ on the speed is negligible thanks to the moment of system inertia. The pulse width of $i_{d} \neq 0$ is set to be $50 \mathrm{~ms}$ and the ill-conditioned problem due to non-ideal voltage measurement can be well solved by using the error analysis. Fig. 9 and Fig. 10 show the estimated stator winding resistance and rotor flux linkage at normal condition (the room temperature is $T=25^{\circ} \mathrm{C}$ ), from which it is obvious that the estimated parameter values are quite close to the nominal values listed in Table I. In addition, since there exist iron losses (See Appendix C) and temperature rise in winding due to on-load, it will cause the estimated winding resistance $(0.388 \Omega)$ slightly larger than the measured winding resistance $(0.373 \Omega)$ at standstill. 


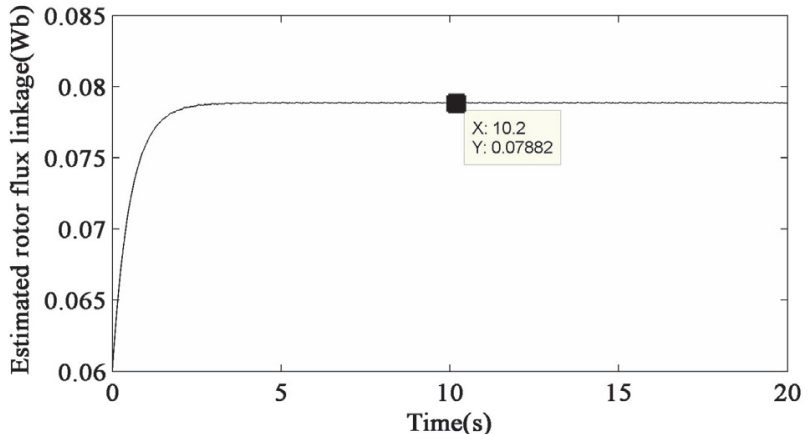

Fig. 10. Rotor flux linkage estimation at normal condition (Motor1).

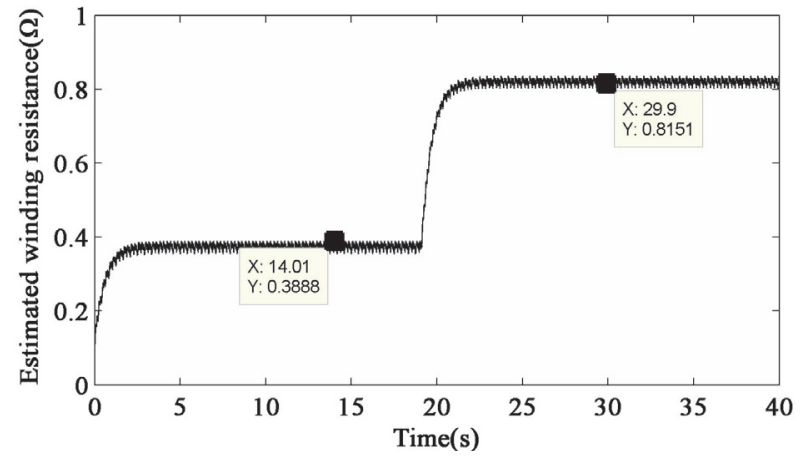

Fig. 11. Estimated winding resistance and its variation (Motor1).

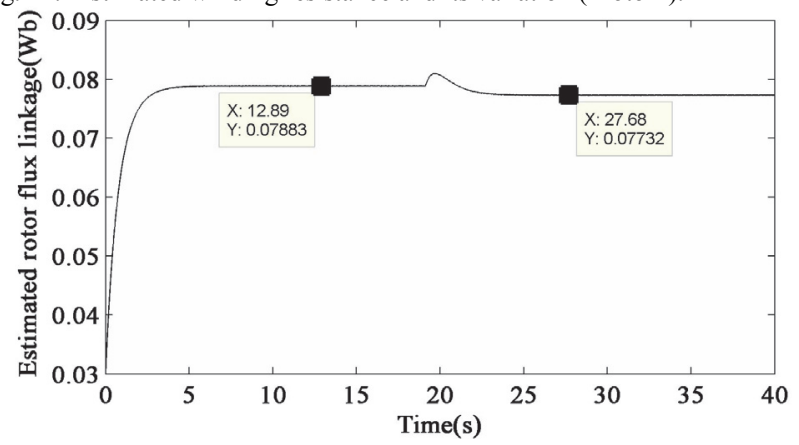

Fig. 12. Estimated rotor flux linkage (Motor1).

TABLE III

ESTIMATED WINDING RESISTANCE VALUE OF MOTOR1 UNDER DIFFERENT INJECTION SCHEMES

\begin{tabular}{|c|c|}
\hline Injected $i_{d}(\mathrm{~A})$ & Estimated $R(\Omega)$ \\
\hline$i_{d}=-2.5$ & 0.520 \\
\hline$i_{d}=-2$ & 0.552 \\
\hline$i_{d}=-1.5$ & 0.725 \\
\hline$i_{d}=-1$ & 0.84 \\
\hline$i_{d}=-0.5$ & 1.48 \\
\hline$i_{d}=0.5$ & 1.19 \\
\hline$i_{d}=1$ & 0.913 \\
\hline$i_{d}=1.5$ & 0.53 \\
\hline$i_{d}=2$ & 0.390 \\
\hline$i_{d}=2.5$ & 0.388 \\
\hline
\end{tabular}

For comparison, three resistors are connected in series with the three phase windings of Motor 1 at $\mathrm{t}=20 \mathrm{~s}$. Each resistor is $R_{\mathrm{p}}=0.414 \Omega$ and the estimation result after the addition of resistors is shown in Fig. 11. It can be seen that the estimated variation of winding resistance $(0.426 \Omega)$ is close to the actual added resistor value. Thus, the proposed method is effective in tracking the variation of winding resistance and can be used for the condition monitoring of stator windings. Furthermore, Fig. 12 shows that the variation of winding resistance has almost no influence on the estimation of rotor flux linkage.

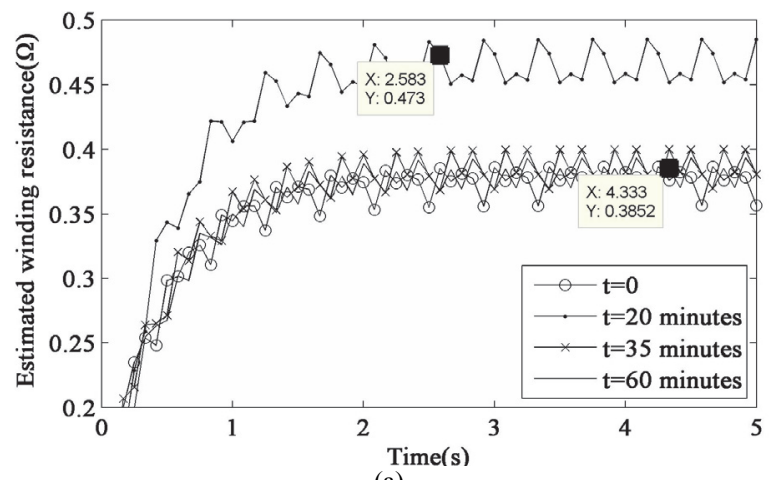

(a)

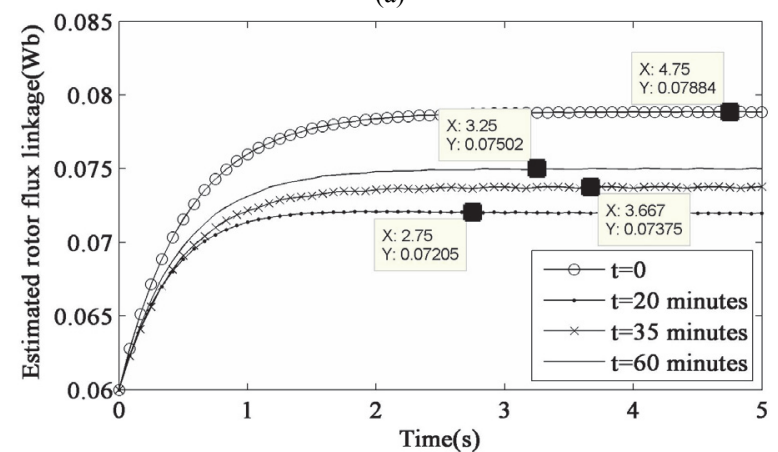

(b)

Fig. 13. Tracking the variation of winding resistance and rotor flux linkage (Motor1).

TABLE IV

VARIATION OF WINDING RESISTANCE AND ROTOR FLUX LINKAGE AT DIFFERENT TIME POINTS (MOTOR1)

$\begin{array}{ccc}\text { Time (minute) } & \text { Estimated } R(\Omega) & \text { Estimated } \psi_{m}(\mathrm{mWb}) \\ \mathrm{t}=0 & 0.388 & 78.8 \\ \mathrm{t}=20 & 0.465 & 72.0 \\ \mathrm{t}=35 & 0.390 & 73.7 \\ \mathrm{t}=60 & 0.385 & 75.0\end{array}$

A heater is used to heat the stator and shaft of PMSM for 20 minutes (from $\mathrm{t}=0$ to $\mathrm{t}=20$ minutes). By using an infrared thermometer, the surface temperature of Motor 1 is measured to be $T=80^{\circ} \mathrm{C}$ at $\mathrm{t}=20$ minutes. For comparison, the winding resistance and rotor flux linkage will be estimated at $\mathrm{t}=0,20,35$ and 60 minutes. Fig. 13 shows the convergence curves of estimated winding resistance and rotor flux linkage at $\mathrm{t}=0,20$, 30 and 60 minutes while the estimated variation of winding resistance and rotor flux linkage are compared in Table IV with their normal values $\left(\mathrm{t}=0\right.$ and $\left.T=25^{\circ} \mathrm{C}\right)$. From Fig. 13 and Table IV, it is evident that the estimated winding resistance will increase from $0.388 \Omega$ to $0.473 \Omega$ after 20 minutes' heating and the winding resistance value will decrease to its normal value soon after the heating is removed.

Different from the variation of winding resistance, the value of rotor flux linkage will decrease from $78.8 \mathrm{mWb}$ to $72.0 \mathrm{mWb}$ after 20 minutes' heating. In addition, since the rotor is covered by the motor end-caps and has worse heat dissipation ability than the stator, the rate at which the rotor flux linkage value increases to its normal value is much slower than the speed of winding resistance.

\section{Experimental Validation on Motor2}

For comparison, the proposed method is also validated on Motor2, which is relatively larger than Motor1 and designed for a small-scale direct-drive wind turbine test rig. 

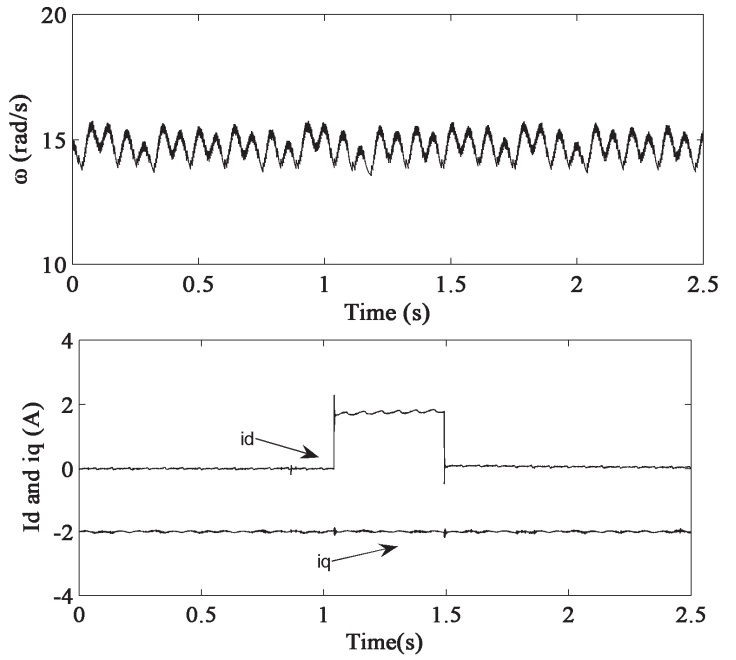

Fig. 14. Waveforms of measured electrical angular speed, $d q$-axis currents, and injected current pulse (Motor2).

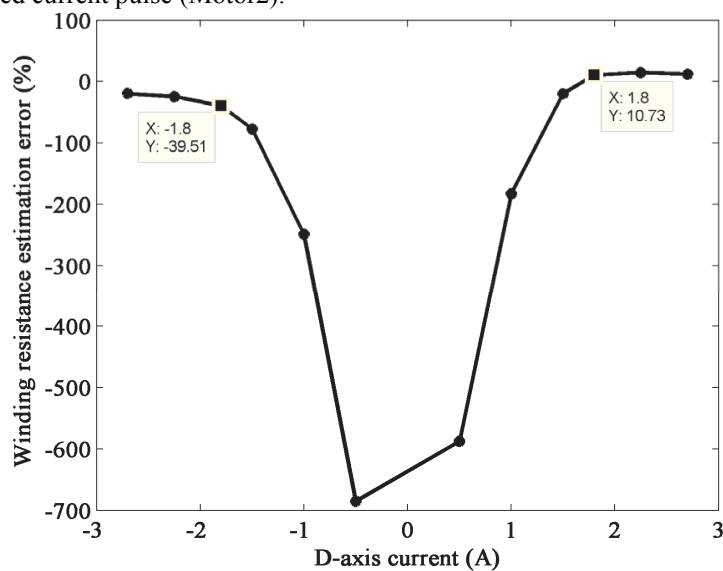

Fig. 15. Actual curve of measured variation of $R_{\text {error }} / R_{a}$ with $i_{d}$ (Motor2).

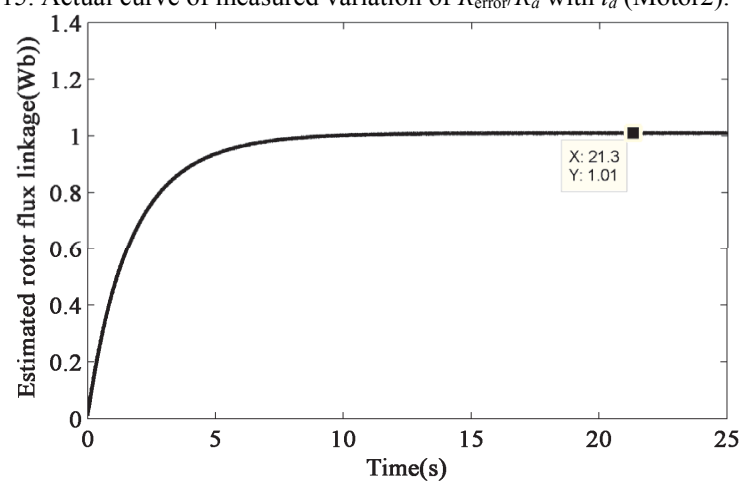

Fig. 16. Rotor flux linkage estimation at 10rpm (Motor2).

Fig. 14 shows the measured electrical angular speed and currents during the estimation, in which Motor2 is working under generator mode and the pulse width of $i_{d} \neq 0$ is set to $500 \mathrm{~ms}$. Fig. 15 shows the error analysis result of Motor2, which is similar to the simulated result of Case1 in Fig. 4 (b). Thus, from Fig. 15, it is preferable to inject id=1.8A for the parameter estimation of Motor2 throughout this paper. From Figs. 16 and 17 , it is obvious that the estimation results at normal condition are close to the nominal values shown in Table II.

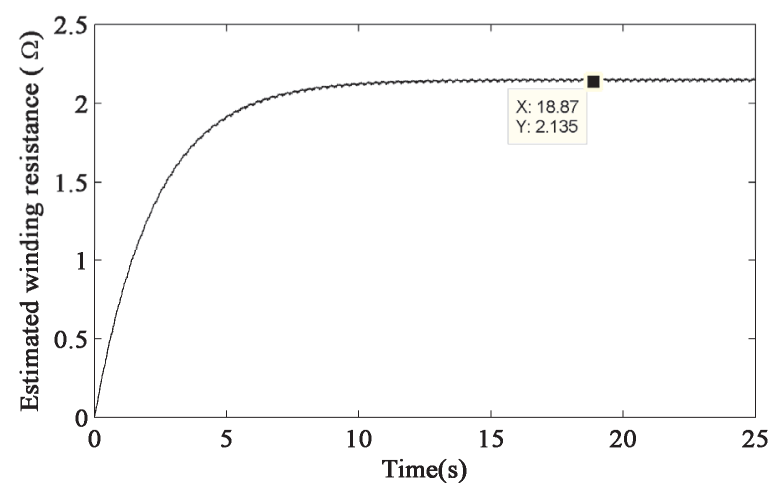

Fig. 17. Winding resistance estimation at 10rpm (Motor2).

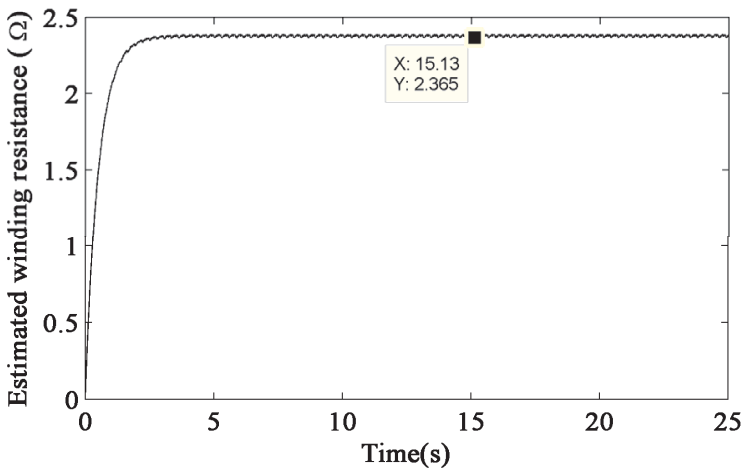

Fig. 18. Estimated winding resistance at $15 \mathrm{rpm}$ (Motor2)

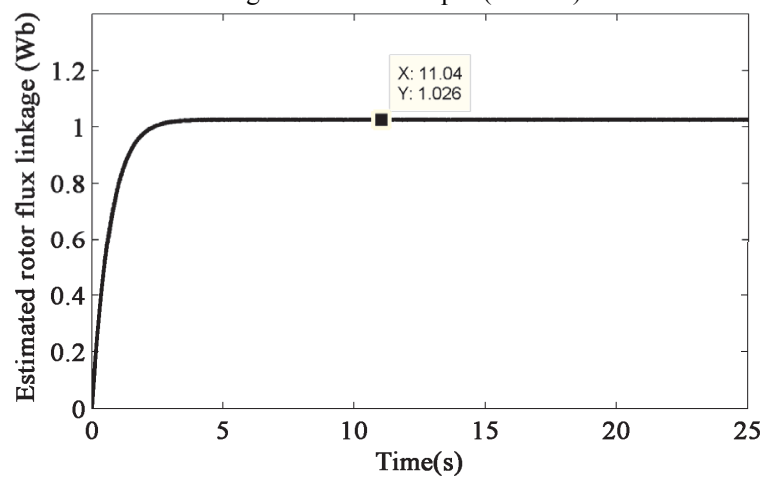

Fig. 19. Estimated rotor flux linkage at $15 \mathrm{rpm}$ (Motor2).

Similar to the experimental results of Motor1, the estimated winding resistance value of Motor2 $(2.135 \Omega)$ at $10 \mathrm{rpm}$ is slightly larger than its nominal value $(2.005 \Omega)$ at standstill, which is caused by the iron losses and temperature rise in winding due to on-load. Similar phenomenon also occurs in the experimental results at 15rpm, as depicted in Figs. 18 and 19. For comparison, a set of three resistors are connected in series with the three phase windings of Motor 2 and each resistor is $R_{d}=1.050 \Omega$. The estimation results after the addition of resistors are depicted in Fig. 20 and Fig. 21, in which show that the estimated abrupt variation in winding resistance (1.155 $\Omega$ ) is

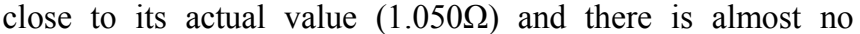
influence on the estimation of rotor flux linkage. Thus, the proposed method still shows good performance in tracking the parameter variation of Motor2. In addition, since the rotor outer diameter of Motor 2 is as large as $426.4 \mathrm{~mm}$ and is much larger than that $(100 \mathrm{~mm})$ of Motor 1 , it is difficult to uniformly heat Motor 2 and the heating experiment is therefore not duplicated on it. 


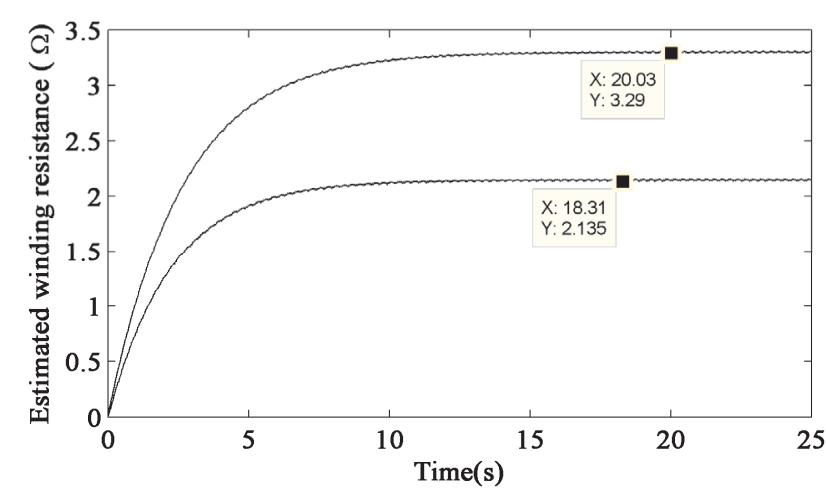

Fig. 20. Estimated winding resistance and its variation at 10rpm (Motor2).

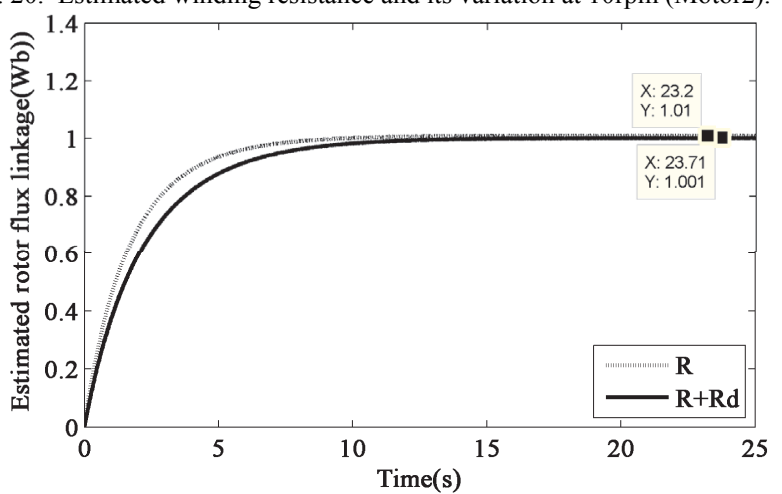

Fig. 21. Estimated rotor flux linkage at 10rpm (Motor2).

\section{CONCLUSIONS}

A new parameter estimation scheme for simultaneously estimating the winding resistance and rotor flux linkage of PMSM has been proposed in this paper, which can be used for condition monitoring of machine stator winding and rotor permanent magnet. This method is based on a proposed full rank model and a short injection of $i_{d} \neq 0$ is needed during the estimation. Different from existing methods[7]-[10], [20] based on injecting $i_{d} \neq 0$, the proposed method does not need the value of $d q$-axis inductances while the rotor flux linkage variation due to injected $i_{d} \neq 0$ is taken into account by using the equation of constant load torque. In addition, the ill-conditioned problem due to non-ideal voltage measurement is investigated and solved by using the error analysis. The experimental validation has shown that the proposed method has good performance in estimating and tracking the variation of winding resistance and rotor flux linkage. Thus, it is suitable for the condition monitoring of non-salient pole PMSM. Further, it has the potential ability to be used for the fault analysis of winding resistance and rotor flux linkage since some real faults, such as winding open/short circuit and damage in the rotor permanent magnet, will cause a significant variation in winding resistance and rotor flux linkage.

\section{Appendix A}

\section{Design Estimators by Adaline NN}

The mathematical model of Adaline NN can be shown as follows:

$O\left(W_{i}, X_{i}\right)=\sum_{i=0}^{n} W_{i} X_{i}$

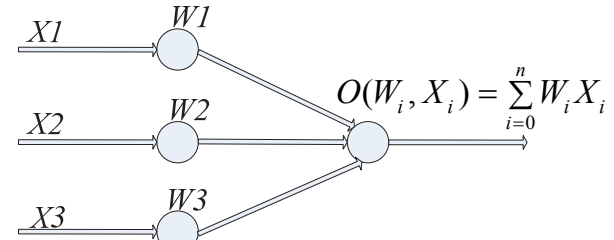

Fig. 22. Structure of an Adaline NN

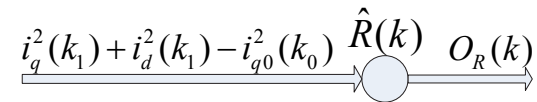

(a) Subnet of winding resistance estimator

$$
\underbrace{\omega\left(k_{0}\right)}_{\hat{R}(k) i_{q_{0}}\left(k_{0}\right)} \underbrace{\hat{\psi}_{m 0}(k)} \underbrace{\hat{u}_{q 0}\left(k_{0}\right)}
$$

(b) Subnet of rotor flux linkage estimator

Fig. 23. Subnets of winding resistance and rotor flux linkage estimators.

where $W_{i}$ is the net weight and $X_{i}$ is the input signal. The activation function $O\left(W_{i}, X_{i}\right)$ of the network output node is a linear function. The general structure of Adaline $\mathrm{NN}$ [25] is shown in Fig. 22. As can be seen from (A.1) and Fig. 22, if $d(k)$ is the measured system output, the weight adjustment can be obtained via LMS [25]:

$W_{i}(k+1)=W_{i}(k)+2 \eta X_{i}(d(k)-O)$

In (A.2), $\eta$ is the convergence factor which adjusts the weight convergence speed. In the proposed method shown in Fig. $2, k_{0}$ will be kept always equal to $k_{1}$ for the convenience of estimator design. Thus, from (9a) and(9b), (A.3) can be obtained:

$u_{q}\left(k_{1}\right) i_{q}\left(k_{1}\right)+u_{d}\left(k_{1}\right) i_{d}\left(k_{1}\right)-u_{q 0}\left(k_{0}\right) i_{q 0}\left(k_{0}\right)$

$$
=R\left(i_{q}^{2}\left(k_{1}\right)+i_{d}^{2}\left(k_{1}\right)-i_{q 0}^{2}\left(k_{0}\right)\right)
$$

From (A.3), the subnet of winding resistance estimator can be expressed as Fig. 23(a), which shows the input and output of the estimator. Assuming

$$
\left\{\begin{array}{l}
W_{i}(k)=\hat{R}(k) \\
d(k)=u_{q}\left(k_{1}\right) i_{q}\left(k_{1}\right)+u_{d}\left(k_{1}\right) i_{d}\left(k_{1}\right)-u_{q 0}\left(k_{0}\right) i_{q 0}\left(k_{0}\right) \\
O=O_{R}(k)=\hat{R}(k)\left(i_{q}^{2}\left(k_{1}\right)+i_{d}^{2}\left(k_{1}\right)-i_{q 0}^{2}\left(k_{0}\right)\right) \\
X_{i}=i_{q}^{2}\left(k_{1}\right)+i_{d}^{2}\left(k_{1}\right)-i_{q 0}^{2}\left(k_{0}\right)
\end{array}\right.
$$

where $\hat{R}(k)$ is the estimated winding resistance and the Adaline estimator can be derived from (A.2) by comparing Fig. 23(a) with Fig. 22 and is shown as follows:

$$
\begin{gathered}
\hat{R}(k+1)=\hat{R}(k)+2 \eta\left(i_{q}^{2}\left(k_{1}\right)+i_{d}^{2}\left(k_{1}\right)-i_{q 0}^{2}\left(k_{0}\right)\right)\left(u_{q}\left(k_{1}\right) i_{q}\left(k_{1}\right)+\right. \\
\left.u_{d}\left(k_{1}\right) i_{d}\left(k_{1}\right)-u_{q 0}\left(k_{0}\right) i_{q 0}\left(k_{0}\right)-O_{R}(k)\right)
\end{gathered}
$$

Similarly, from $(9 b)$, the subnet of rotor flux linkage estimator can be expressed as Fig. 23(b), which shows the input and output of the estimator. Assuming

$$
\left\{\begin{array}{l}
W_{i}(k)=\hat{\psi}_{m 0}(k) \\
d(k)=u_{q 0}\left(k_{0}\right)-\hat{R}(k) i_{q 0}\left(k_{0}\right) \\
O=\hat{u}_{q 0}(k)-\hat{R}(k) i_{q 0}\left(k_{0}\right)=\hat{\psi}_{m 0}(k) \omega\left(k_{0}\right) \\
X_{i}=\omega\left(k_{0}\right)
\end{array}\right.
$$

where $\hat{\psi}_{m 0}(k)$ is the estimated rotor flux linkage. Thus, the rotor 
flux linkage estimator can be derived from (A.2) by comparing Fig. 23(b) with Fig. 22 and is shown as follows:

$\hat{\psi}_{m 0}(k+1)=\hat{\psi}_{m 0}(k)+2 \eta \omega\left(k_{0}\right)\left(u_{q 0}\left(k_{0}\right)-\hat{u}_{q 0}(k)\right)$

$\hat{R}(k)$ is transferred from (A.4) in each step of estimation.

Appendix B

Ill-conditioned Problem

Consider systems

$$
\left\{\begin{array} { l } 
{ x + y = 2 } \\
{ x + 1 . 0 0 1 y = 2 }
\end{array} \text { and } \left\{\begin{array}{l}
x+y=2 \\
x+1.001 y=2.001
\end{array}\right.\right.
$$

The system on the left has solution $x=2, y=0$ while the one on the right has solution $x=1, y=1$. The coefficient matrix is called ill-conditioned because a small change in the constant coefficients or in the variables $(\mathrm{x}, \mathrm{y})$ will result in a large change in the solution. For a coefficient matrix A, the condition number $(\operatorname{cond}(\mathrm{A}))$ is utilized to judge whether it is a well-conditioned matrix, which is defined as follows:

$$
\operatorname{cond}(\mathrm{A})_{v}=\left\|\mathrm{A}^{-1}\right\|_{v}\|\mathrm{~A}\|_{v}
$$

where ' $v$ ' is the operator norm of matrix $A$, which can be 1,2 or $\infty$. The system equations are called ill-conditioned if $\operatorname{cond}(\mathrm{A})_{\mathrm{v}}$ is much larger than 1 , or else, they are called well-conditioned. Appendix C

Core-loss Resistance

Assuming that $R_{c}$ is the core-loss resistance (or iron-loss resistance) caused by the rotor-PM and stator armature-reaction fluxes, the PMSM voltage equations in steady-state condition can be written as [19], [31]:

$$
\left\{\begin{array}{l}
u_{d}=R_{e} i_{d}+\frac{\omega^{2} L_{q} \psi_{m}}{R_{c}}-L_{q} \omega i_{q}+L_{d} \frac{d i_{d}}{d t} \\
u_{q}=R_{e} i_{q}+L_{d} \omega i_{d}+\psi_{m} \omega+L_{q} \frac{d i_{q}}{d t}
\end{array}\right.
$$

where $\quad R_{e}=R+\frac{\omega^{2} L_{d} L_{q}}{R_{c}}$ and $\left|\frac{\omega\left(k_{1}\right) L_{q}}{R_{c}}\right| \ll 1 \quad[19]$. Thus, compared with (1), it is obvious from (C.1) that the resistance term $R_{e}$ including the winding resistance and core-loss term will be slightly larger than the winding resistance $R$ at standstill. Thus, in real application, the heat resistance losses of a PMSM should be larger than its copper loss. Taking Motor2 as an example, the estimated value of iron loss versus copper loss at full load by using SPEED software is $26 \%$ and is not negligible. Furthermore, by taking into account the core-loss resistance, (9) will become (C.2).

$$
\left\{\begin{array}{l}
u_{q}\left(k_{1}\right) i_{q}\left(k_{1}\right)+u_{d}\left(k_{1}\right) i_{d}\left(k_{1}\right)= \\
R_{e}\left(i_{q}^{2}\left(k_{1}\right)+i_{d}^{2}\left(k_{1}\right)\right)+\psi_{m 0} \omega\left(k_{1}\right)\left(i_{q 0}\left(k_{0}\right)+\frac{\omega\left(k_{1}\right) L_{q}}{R_{c}} i_{d}\left(k_{1}\right)\right) \\
u_{q 0}\left(k_{0}\right)=R_{e} i_{q 0}\left(k_{0}\right)+\psi_{m 0} \omega\left(k_{0}\right)
\end{array}\right.
$$

where $\left|i_{q 0}\left(k_{0}\right)\right| \gg\left|\frac{\omega\left(k_{1}\right) L_{q}}{R_{c}} i_{d}\left(k_{1}\right)\right|$ in real application. Thus, C.2 can be simplified to be:

$$
\left\{\begin{array}{c}
u_{q}\left(k_{1}\right) i_{q}\left(k_{1}\right)+u_{d}\left(k_{1}\right) i_{d}\left(k_{1}\right)= \\
R_{e}\left(i_{q}^{2}\left(k_{1}\right)+i_{d}^{2}\left(k_{1}\right)\right)+\psi_{m 0} \omega\left(k_{1}\right) i_{q 0}\left(k_{0}\right) \\
u_{q 0}\left(k_{0}\right)=R_{e} i_{q 0}\left(k_{0}\right)+\psi_{m 0} \omega\left(k_{0}\right)
\end{array}\right.
$$

(C.3) has the same form as (9) but with a larger resistance term $R_{e}>R$. Thus, in real application, the estimated winding resistance based on (9) will be slightly larger than the measured winding resistance at standstill due to the core-loss resistance (or iron losses).

\section{REFERENCES}

[1] S. Ichikawa, M. Tomita, S. Doki, and S. Okuma, "Sensorless control of permanent-magnet synchronous motors using online parameter identification based on system identification theory," IEEE Trans. Ind. Electron., vol. 53, no. 2, pp. 363-372, Apr. 2006.

[2] L. Liu, and D.A. Cartes, "Synchronisation based adaptive parameter identification for permanent magnet synchronous motors," IET Proc. Control Theory \& Applicat., vol. 1, no. 4, pp. 1015-1022, Jul. 2007.

[3] M. Rashed, P.F.A. Macconnell, A.F. Stronach, and P. Acarnley, "Sensorless indirect-rotor-field-orientation speed control of a permanent-magnet synchronous motor with stator-resistance estimation," IEEE Trans. Ind. Electron., vol. 54, no. 3, pp. 1664-1675,Jun. 2007.

[4] X. Xiao, C.M. Chen, and M. Zhang, "Dynamic permanent magnet flux estimation of permanent magnet synchronous machines," IEEE Trans. Applied Superconductivity, vol. 20, no. 3, pp. 1085-1088, Mar. 2010.

[5] B. N. Mobarakeh, F. Meibody-Tabar, and F.M. Sargos, "Mechanical sensorless control of PMSM with online estimation of stator resistance," IEEE Trans. Ind. Applicat., vol. 40, no. 2, pp. 457-471, Mar./Apr. 2004.

[6] M.N. Uddin, and M.M.I. Chy, "Online parameter-estimation-based speed control of PM AC motor drive in flux-weakening region," IEEE Trans. Ind. Applicat., vol. 44, no. 5, pp. 1486-1494, Sep./Oct. 2010.

[7] Z.Q. Zhu, X. Zhu, and P.D. Sun, "Estimation of winding resistance and PM flux-linkage in brushless AC machines by reduced-order extended Kalman Filter," in Proc. 2007 IEEE International Conf. Networking, Sensing and Control, 2007, pp. 740-745.

[8] K.W. Lee, D.H. Jung, and I.J. Ha, "An online identification method for both stator resistance and back-EMF coefficient of PMSMs without rotational transducers," IEEE Trans. Ind. Electron., vol. 51, no. 2, pp. 507-510, Apr. 2004.

[9] R. Krishnan, and P. Vijayraghavan, "Fast estimation and compensation of rotor flux linkagein permanent magnet synchronous machines," in Proc. IEEE International Symposium Ind. Electron., 1999, vol. 2, pp. 661-666.

[10] S. Underwood, and I. Husain, "On-line parameter estimation and adaptive control of permanent magnet synchronous machines," IEEE Trans. Ind. Electron., vol. 57, no. 7, pp. 2435-2443, Jul. 2010.

[11] S.D. Wilson, P. Stewart, and B.P. Taylor, "Methods of resistance estimation in permanent magnet synchronous motors for real-time thermal management," IEEE Trans. Energy Convers., vol. 25, no. 3, pp. 698-707, Sep. 2010.

[12] S.B. Lee, and T.G. Habetler, "An online stator winding resistance estimation technique for temperature monitoring of line-connected induction machines," IEEE Trans. Ind. Applicat., vol. 39, no. 3, pp. 685-694, May/Jun. 2003.

[13] P.J. Zhang, B. Lu, and T.G. Habetler, "A remote and sensorless stator winding resistance estimation method for thermal protection of soft-starter-connected induction machines," IEEE Trans. Ind. Electron., vol. 55, no. 10, pp. 3611-3618, Oct. 2008.

[14] M.A. Jabbar, J. Dong, and Z. Liu, "Determination of machine parameters for internal permanent magnet synchronous motors," in Proc. Power Electron., Machines and Drives, 2004, vol. 2, pp. 805-810.

[15] U. Schaible, and B. Szabados, "Dynamic motor parameter identification for high speed flux weakening operation of brushless permanent magnet synchronous machines," IEEE Trans. Energy Conversion, vol.14, no.3, pp. 486-492. Sep. 1999.

[16] D.D. Reigosa, F. Briz, P. Gacia, J.M. Guerrero, and M.W. Degner, "Magnet temperature estimation in surface PM machines using high-frequency signal injection," IEEE Trans. Ind. Applicat., vol. 46, no. 4, pp. 1468-1475, Jul./Aug. 2010.

[17] R. Ramakrishnan, R. Islam, M. Islam, and T. Sebastian, "Real time estimation of parameters for controlling and monitoring permanent magnet synchronous motors," in Proc. IEEE International Electric Machines and Drives Conf., Miami, Florida, 2009, pp. 1194-1199. 
[18] A. Piippo, M. Hinkkanen, and J. Luomi, "Adaptation of Motor Parameters in Sensorless PMSM Drives," IEEE Trans. Ind. Applicat., vol. 45, no. 1, pp:203-212, Jan./Feb. 2009.

[19] T. Senjyu, Y. Kuwae, N. Urasaki and K. Uezato, "Accurate parameter measurement for high speed permanent magnet," in Proc. IEEE Power Electron. Specialists Conf., 2001, vol. 2, pp. 772-777.

[20] S. Morimoto, M. Sanada, and Y. Yakeda, "Mechanical sensorless drives of IPMSM with online parameter identification," IEEE Trans. Ind. Applicat., vol. 42, no. 5, pp. 1241-1248, Sep./Oct, 2006.

[21] S.B. Lee, "Closed-loop estimation of permanent magnet synchronous motor parameters by PI controller gain tuning," IEEE Trans. Energy Convers., vol. 21, no. 4, pp. 863-870, Dec. 2006.

[22] K. Liu, Q. Zhang, J.T. Chen, Z.Q. Zhu, J. Zhang, and A.W. Shen, “Online multiparameter estimation of non-salient pole PM synchronous machines with temperature variation tracking," IEEE Trans. Ind. Electron., vol. 58 , no. 5, pp. 1776-1788, May 2011.

[23] A.M.N. Lima, C.B. Jacobina, and E.B.D.S Filho, "Nonlinear parameter estimation of steady-state induction machine models," IEEE Trans. Ind. Electron., vol. 44, no. 3, pp. 390-397, Jun. 1997.

[24] M. Wlas, Z. Krzeminski, and H.A. Toliyat, "Neural-network-based parameter estimations of induction motors," IEEE Trans. Ind. Electron. vol. 55, no. 4, pp. 1783-1794, Apr. 2008.

[25] B. Widrow, and M.A. Lehr, "30 years of adaptive neural networks: percentron, MAdaline, and backpropagation," Proc. of the IEEE, vol. 78 no. 9, pp. 1415-1442, Sep. 1990.

[26] H.W. Kim, M.J. Youn, and K.Y. Cho, "New voltage distortion observer of PWM VSI for PMSM," IEEE Trans. Ind. Electron., vol. 52, no. 4, pp. 1188-1192, Aug. 2005.

[27] S.Y. Kim, W. Lee, M.S. Rho, and S.Y. Park, "Effective dead-time compensation using a simple vectorial disturbance estimator in PMSM drives," IEEE Trans. Ind. Electron., vol. 57, no. 5, pp. 1609-1614, May 2010.

[28] K. Liu, Z.Q. Zhu, Q. Zhang, and J. Zhang, "Influence of nonideal voltage measurement on parameter estimation in permanent magnet synchronous machines," IEEE Trans. Ind. Electron., vol. 59, no. 6, pp. 2438-2447, Jun. 2012.

[29] J.W. Choi, and S.K. Sul, "Inverter output voltage synthesis using novel dead-time compensation," IEEE Trans. Power Electron., vol. 11, no. 2, pp. 221-227, Mar. 1996

[30] T. Boileau, N. Leboeuf, B. Nahid-Mobarakeh, and F. Meibody-Tabar, "Online identification of PMSM parameters: parameter identifiability and estimator comparative study," IEEE Trans. Ind. Applicat., vol. 47, no. 4, pp. 1944-1957, Jul./Aug. 2011

[31] I. Lar, and M.M. Radulescu, "Equivalent core-loss resistance identification for interior permanent-magnet synchronous machines," in Proc. IEEE International Conf. Electrical Machines, 2012, vol. 2, pp. 1665-1669.

[32] M.A. Hamida, J.D. Leon, A. Glumineau, and R. Boisliveau, “An adaptive interconnected observer for sensorless control of PM synchronous motors with online parameter identification," IEEE Trans. Ind. Electron., vol. 60, no. 2, pp. 739-748, Feb. 2013.

[33] G. Gatto, I. Marongiu, and A. Serpi, "Discrete-time parameters identification of a surface-mounted permanent magnet synchronous machine,” IEEE Trans. Ind. Electron., vol. PP, no. 99, pp. 1-12, 2012.

[34] Y. Shi, K. Sun, L. Huang, and Y. Li, "Online identification of permanent magnet flux based on extended Kalman filter for IPMSM drive with position sensorless control," IEEE Trans. Ind. Electron., vol. 59, no. 11 , pp. 4169-4178, Nov. 2012

[35] Y. Inoue, Y. Kawaguchi, S. Morimoto, and M. Sanada, "Performance improvement of sensorless IPMSM drives in a low-speed region using online parameter identification," IEEE Trans. Ind. Applicat., vol. 47, no. 2, pp. 798-804, Mar./Apr. 2011.

[36] Y. Inoue, K. Yamada, S. Morimoto, and M. Sanada, "Effectiveness of voltage error compensation and parameter identification for model-based sensorless control of IPMSM," IEEE Trans. Ind. Applicat., vol. 45, no. 1 , pp. 213-221, Jan./Feb. 2009

[37] M. Hasegawa, and K. Matsui, "Position sensorless control for interior permanent magnet synchronous motor using adaptive flux observer with inductance identification," IET Proc. Electric Power Applicat., vol. 3, no. 3, pp. 209-217, Aug. 2008 .
[38] M. Hinkkanen, T. Tuovinen, L. Harnefors, and J. Luomi, “A combination position and stator-resistance observer for salient PMSM drives: design and stability analysis," IEEE Trans. Power Electron., vol. 27, no. 2, pp. 601-609, Feb. 2012.

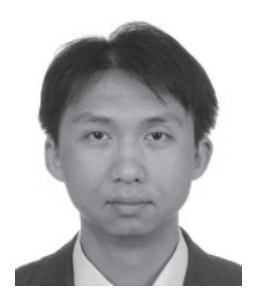

Kan Liu received the B.Eng. and Ph.D. degrees in automation (control theory and control engineering) from the Hunan University, China, in 2005 and 2011, respectively. $\mathrm{He}$ is currently working in the Department of Electronics and Electrical Engineering at the University of Sheffield. His research interest focuses on brushless AC motor parameters estimation by control theory, sensorless control and nonlinearity compensation for voltage source inverter output voltage.

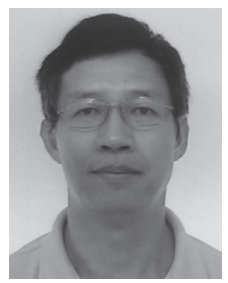

Z. Q. Zhu (M'90-SM'00-F'09) received the B.Eng. and M.Sc. degrees in electrical and electronic engineering from Zhejiang University, Hangzhou, China, in 1982 and 1984, respectively, and the Ph.D. degree in electrical and electronic engineering from the University of Sheffield, Sheffield, U.K., in 1991. From 1984 to 1988 , he was a Lecturer with the Department of Electrical Engineering, Zhejiang University. Since 1988, he has been with the University of Sheffield, where he was initially a Research Associate and was subsequently appointed to an established post as Senior Research Officer/Senior Research Scientist. Since 2000, he has been a Professor of Electrical Machines and Control Systems with the Department of Electronic and Electrical Engineering, University of Sheffield, and is currently Head of the Electrical Machines and Drives Research Group and Director of Sheffield Siemens Wind Power Research Centre. His current major research interests include design and control of permanent magnet brushless machines and drives, for applications ranging from automotive, aerospace, to renewable energy. He is a Fellow of IEEE.

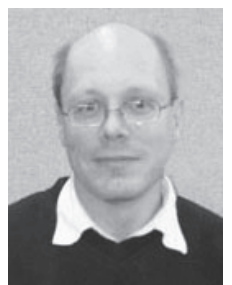

David A. Stone received the B.Eng. degree in electronic engineering from The University of Sheffield, Sheffield, U.K., in 1984 and the Ph.D. degree from Liverpool University, Liverpool, U.K., in 1989. He returned to The University of Sheffield as a member of Academic Staff specializing in power electronics and machine drive systems in the Department of Electrical and Electronic Engineering. His current research interests are in hybrid-electric vehicles, battery charging, electromagnetic compatibility, and novel lamp ballasts for low pressure fluorescent lamps. 